\title{
Correction to: Effectiveness comparisons of antiviral treatments for Bell palsy: a systematic review and network meta-analysis
}

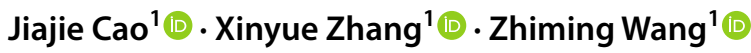

Published online: 1 February 2022

(c) The Author(s), under exclusive licence to Springer-Verlag GmbH Germany 2022

Correction to: Journal of Neurology

https://doi.org/10.1007/s00415-021-10487-9

The original version of this article unfortunately contained a mistake. The Funding information section was missing and Funding information should read as:

The article was supported by "345 Talent Project of Shengjing Hospital”.

The original article has been corrected.

The original article can be found online at https://doi.org/10.1007/ s00415-021-10487-9.

Zhiming Wang

48658198@qq.com

1 Department of Stomatology, Shengjing Hospital of China Medical University, Shenyang 110004, LN, China 